\title{
REDAÇÃO NO EXAME NACIONAL DO ENSINO MÉDIO (ENEM) E SISTEMA DE APOSTILADO DA REDE PRIVADA Confluências ou conflitos? ${ }^{1}$
}

\author{
Alyne Barbosa Lima ${ }^{2}$ \\ Silvio Ribeiro da Silva ${ }^{3}$
}

RESUMO: Este artigo tem por intuito apresentar os resultados de uma pesquisa PIBIC/CNPq sobre as atividades de produção de textos escritos em material didático (MD) apostilado de um sistema de ensino privado de grande alcance nacional, associando as propostas de produção do material às competências da prova de Redação do Exame Nacional do Ensino Médio (ENEM). O principal objetivo é verificar se as propostas de produção de texto escrito vão ao encontro das competências da prova de Redação do ENEM, buscando indícios se o material didático pode ou não colaborar com o aluno, instrumentalizando-o para um melhor desempenho na Redação a partir da abordagem das competências nas atividades de escrita. Para tanto, recorre-se à pesquisa qualitativo-interpretativista, adotando-se as contribuições teóricas e metodológicas dos escritos do Círculo de Bakhtin, no que tange aos conceitos de interação verbal, tema e gêneros do discurso, bem como de Schneuwly, Dolz e colaboradores, com sua proposta didática para o ensino de francês/língua materna, adaptada à realidade de ensino no Brasil. Os resultados mostram que o MD em análise aborda de maneira desequilibrada as competências do ENEM, bem como tende a desconsiderar as condições de produção do texto escrito.

Palavras-chave: Redação. ENEM. Material didático.

\section{WRITING OF THE NATIONAL HIGH SCHOOL EXAM (ENEM) AND THE PRIVATE NETWORK'S APOSTILLE SYSTEM Confluences or conflicts?}

\begin{abstract}
This paper aims to present the results of a research PIBIC/CNPq about the activities of written texts production in a private national education system textbook, associating its production proposals with the skills demanded by the ENEM (Exame Nacional do Ensino Médio - High School National Exam) writing test. The main objective is to verify whether the written texts production proposals meet the ENEM writing test skills, seeking indications as to whether the textbook may or may not collaborate with the student, instrumentalizing him for a better performance on the writing test from the approach of the skills in its writing activities. In order to do so, it is used a qualitativeinterpretative research, adopting as theoretical and methodological contributions the Circle of Bakhtin writings, concerning the concepts of verbal interaction, theme and discourse genres, as well as
\end{abstract}

\footnotetext{
${ }^{1}$ Este estudo contribui com as pesquisas acadêmicas sobre o tema e ainda com aqueles realizados dentro do Grupo de Estudos sobre Materiais Didáticos, Ensino e Avaliação - GEMDAV (***/CNPq), bem como do Grupo de Estudos da Linguagem: análise, descrição e ensino (***/CNPq).

${ }^{2}$ Graduanda em Letras Português. Bolsista Cnpq. Universidade Federal de Goiás-Regional Jataí

${ }^{3}$ Graduado em Letras Português (UFG). Mestre em Linguística (UFU). Doutor em Linguística Aplicada (UNICAMP) Professor Adjunto 3 (UFG/REJ)
} 
Volume, 14, número 1, ano 2018.

Schneewly, Dolz and collaborators with their didactic proposal for French/mother tongue teaching, adapted to the reality of Brazil's teaching. The results show that the textbook in analysis approaches ENEM skills in an unbalanced way, as well as tends to disregard the written texts' conditions of production.

Key-words: Writing. ENEM. Textbook.

\section{INTRODUÇÃO}

A escolha por determinado assunto para que dele seja realizada uma pesquisa não ocorre por acaso. Na verdade, é resultado de algumas questões que se colocam perante certa realidade. Tais questões, de maneira geral, trazem no seu bojo uma carga de valores e pressupostos que não apenas revelam o contexto sócio histórico em que nos encontramos, mas também o contexto do próprio objeto que pretendemos pesquisar.

Neste artigo, apresentamos os resultados de uma pesquisa sobre as atividades de produção de textos escritos em material didático, mais precisamente no sistema de apostilados da Rede Pitágoras de Ensino (Ensino Médio - EM), associando as propostas de produção do material às competências da prova de Redação do Exame Nacional do Ensino Médio (ENEM).

Material didático são obras produzidas para auxiliar no ensino de uma determinada disciplina. Para se chegar a esse intento, apresenta-se um conjunto extenso de conteúdos do currículo, considerando uma progressão curricular, concretizada em forma de unidades ou lições. Essas unidades ou lições são organizadas de modo a favorecer usos coletivos (na escola) e individuais (em casa ou em classe) (CHOPPIN, 2008).

Atualmente, muitas das apostilas produzidas pela rede privada exercem a mesma função do livro didático, deixando de ocupar o lugar de apenas complementares a ele. Seu papel hoje é o de substituí-lo completamente em muitas escolas (SALOMÃO, 2007). O livro didático ser substituído pelo sistema de apostilado é uma ocorrência cuja razão está ligada ao amplo desenvolvimento do ensino privado, especialmente nas duas últimas décadas, e ao desinteresse do Governo Federal pelo ensino oferecido por essas instituições (BUNZEN, 2001). A apostila, na atualidade, representa modernização e sua adoção está vinculada ao ideal de progresso, eficiência e dinamismo (ARRUDA, KINJO \& BARBOSA, s/d).

As questões motivadoras do estudo que deu origem a este artigo foram: (i) o baixo desempenho dos alunos da unidade escolar usuária do sistema de apostilado da Rede 
Volume, 14, número 1, ano 2018.

Pitágoras de Ensino em 2014, em Jataí (GO), na prova de Redação do Exame Nacional do Ensino Médio (ENEM), está associado à concepção de produção escrita adotada pelo material didático (MD), que desconsidera as competências expressas na matriz de referência para Redação?; (ii) o baixo desempenho dos alunos se deve a uma metodologia adotada pelo MD a qual privilegia um ensino mais normativo, baseado em atividades de codificação, decodificação?; (iii) a concepção de linguagem e de texto escrito que se sobressai nas atividades de produção de texto do MD é aquela que favorece os sentidos presentes na linguagem em uso?

A respeito da escolha do material didático analisado, ela se deu a partir da observação da pontuação mais baixa obtida pelas três escolas da esfera privada da cidade de Jataí GO na prova de Redação no exame de 2014. Neste ano, em Jataí, das sete (07) unidades escolares privadas, cujos alunos fizeram a avaliação do ENEM, os três resultados mais baixos na prova de Redação foram (em ordem crescente): 480; 562,35; 573,33 ${ }^{4}$. Os dois resultados mais baixos foram obtidos por unidades escolares usuárias de sistemas de apostilados com pouca abrangência no território nacional: FTD-Sistema de Ensino e Sistema Ari de Sá, respectivamente ${ }^{5}$. Já a terceira nota mais baixa foi alcançada por uma unidade escolar usuária do sistema de apostilados da Rede Pitágoras.

A Rede Pitágoras de Ensino tem um grande alcance no segmento privado de Educação Básica no país, com abrangência nacional e internacional, tendo iniciado suas atividades na década de 60 do século passado no Brasil. Já nos anos 80, a rede iniciou suas atividades no exterior, com a abertura de unidades na Mauritânia (no noroeste da África) e no Iraque (no Oriente Médio). No final dos anos 2000, a Kroton Educacional começou a atuar no sistema de ensino, permitindo uma grande expansão da Rede Pitágoras. A partir de então, a Rede Pitágoras passou a abranger uma grande área do território nacional, não só com escolas, mas também investindo no ensino superior e na pós-graduação. Na Educação Básica, a Rede Pitágoras, atualmente, se integra com mais de 600 escolas parceiras espalhadas por todo o

\footnotetext{
${ }^{4}$ FONTE: http://portal.inep.gov.br/web/enem/enem-por-escola. Acesso em 01 de fevereiro de 2016.

${ }^{5}$ FTD - Sistema de Ensino abrange uma média de 200 escolas no país. Já o Sistema Ari de Sá abrange uma média de 500 escolas. FONTES: http://revistaeducacao.com.br/textos/128/artigo234304-1.asp (acesso em 05 de fevereiro de 2016); http://www.portalsas.com.br/features/abrangencia-ari-de-sa (acesso em 05 de fevereiro de 2016).
} 
Volume, 14, número 1, ano 2018.

Brasil, contando com mais de 200 mil alunos ${ }^{6}$. Toda essa abrangência do material didático da Rede Pitágoras motiva um estudo investigatório como o que ora apresentamos.

Com base na abrangência de uso do material adotado por uma das unidades escolares com nota mais baixa na cidade, a justificativa para escolher o material da Rede Pitágoras de Ensino se efetiva: (i) trata-se de um material usado por um grande número de alunos; (ii) o material é adotado por uma escola que teve um índice de participação de alunos considerável na avaliação do ENEM em 2014 ; (iii) o material da Rede Pitágoras de Ensino não passa por processos de avaliação oficial ${ }^{8}$.

Em se tratando de um estudo que usa como referências o modelo de avaliação do ENEM, sua pertinência está no fato de que ele passa distante do entendimento tão comum até então de encarar o aluno apenas como um depositário passivo, cabendo a este somente um esforço mecânico de memorização de fatos, regras e conceitos. $\mathrm{O}$ exame não concebe $\mathrm{o}$ processo de ensino-aprendizagem como uma transferência do conhecimento do professor, detentor absoluto do saber, para o aluno. O ENEM solicita do aluno domínio de competências na solução de problemas, colocando em uso conhecimentos que vieram sendo adquiridos na escola e nas experiências pessoais extraescolares. Assim, segundo o INEP, não interessa ao ENEM medir a capacidade que o aluno tem para assimilar e acumular informações. Ao contrário disso, o exame quer saber como o aluno utiliza essas informações em contextos adequados e como constrói sentido para códigos e linguagens, fazendo uso dos conhecimentos adquiridos para tomar decisões autônomas e socialmente relevantes. Por isso, tornou-se importante analisar se o material didático levava em conta o que o ENEM mensura, tendo em vista que a metodologia do referido exame se sobressai em relação a outras práticas ainda comuns na escola. Segundo Marcuschi (2006), o quadro de competências adotado pelo ENEM expressa o currículo básico esperado no Ensino Médio, evidenciado por uma

\footnotetext{
${ }^{6}$ FONTE: http://www.redepitagoras.com.br/pagina/21/nossa-trajetoria.aspx. Acesso em 01 de fevereiro de 2016.

${ }^{7} \mathrm{O}$ resultado por escola só é divulgado para as escolas que cumpriram, concomitantemente, os dois critérios a seguir: a) possuir pelo menos 10 (dez) alunos concluintes do ensino médio regular seriado participantes do Enem; e b) possuir pelo menos 50\% de alunos participantes do Enem, de acordo com os dados do Censo Escolar. Segundo o INEP, o colégio usuário do Sistema Pitágoras teve, em 2014, um índice de participação dos alunos de 71,43\%. FONTE: http://portal.inep.gov.br/web/enem/enem-por-escola. Acesso em 01 de fevereiro de 2016.

${ }^{8}$ Segundo Pedrosa (2006), é visível a melhoria na qualidade dos materiais didáticos (livros didáticos) que chegam aos alunos após a implantação do Programa Nacional do Livro Didático (PNLD). Como o material do sistema privado não é avaliado, não é de conhecimento seu nível de qualidade, muito menos se ele trabalha o desenvolvimento de competências e habilidades que podem desenvolver os letramentos do aluno.
} 
Volume, 14, número 1, ano 2018.

associação de competências e habilidades tidas como necessárias no decorrer do processo de construção do conhecimento da formação média. Outro motivo que justifica um estudo que fizesse uso da metodologia de avaliação do ENEM está no fato de que essa avaliação mensura não somente o uso de competências e habilidades, mas os relaciona aos saberes das diversas áreas do conhecimento, privilegiando a leitura e a interdisciplinaridade, sendo que esta permite a articulação dos saberes, dando às disciplinas vitalidade e fecundidade (MORIN, 2002).

Sendo a produção de textos um componente do currículo escolar, para pesquisar seu ensino buscamos orientação nas ideias do interacionismo e da perspectiva enunciativodiscursiva de Schneuwly (1988), cujo foco está centrado menos na estrutura do texto e na cognição individual e mais na interação enunciativo-discursiva do sujeito com a situação social de produção. Esta perspectiva acerca da produção de texto ainda é pouco conhecida no Brasil. Porém, acreditamos ser um avanço em relação às demais, tendo em vista a ênfase que a mesma dá à função primordial da interação social e da enunciação ao longo de todo o processo de produção do texto.

Esclarecemos que toda a reflexão ligada a este estudo está na compreensão da "linguagem como uma realidade impregnada de social, construída a partir de uma necessidade humana que serve de trama a todas as relações sociais em todos os domínios" (BAKHTIN/VOLOCHÍNOV, 1981, p. 38).

Os objetivos traçados para a realização do estudo foram: (i) Analisar se os saberes (capacidades discursivas - SCHNEUWLY \& DOLZ, 2010) mobilizados pelas propostas de produção escrita do apostilado da Rede Pitágoras (Ensino Médio) vão ao encontro das competências da Matriz de Referência para Redação do ENEM, considerando a prioridade que têm para a produção de um texto escrito de qualidade; (ii) Levantar hipóteses acerca do insucesso dos alunos da Rede Pitágoras em Jataí (GO) na prova de Redação, analisando se ele pode ter sido motivado pelas propostas de produção escrita do MD não trabalharem o desenvolvimento das competências requeridas pela avaliação do ENEM; (iii) Verificar se as atividades de produção de texto escrito apresentadas pelo MD contribuem para uma aprendizagem efetiva de escrita, considerando as condições de produção do texto.

Para o alcance dos objetivos elencados, propusemos um estudo que se baseou nos procedimentos metodológicos da Linguística Aplicada (LA). Moita Lopes (2005) diz que a 
Volume, 14, número 1, ano 2018.

pesquisa desenvolvida pela LA é aplicada, ocorre no contexto de aplicação, isto é, no contexto de ação, e não se faz aplicação em LA, ou seja, a LA não consiste em simplesmente aplicar teorias desenvolvidas pela Linguística. Rojo (2006, p. 258) reitera a afirmação de Moita Lopes, dizendo que em LA "não se busca aplicar uma teoria a um dado contexto para testá-la". Em outras palavras, enquanto a Linguística objetiva desenvolver o conhecimento muito mais pelo conhecimento em si, a LA tem como meta a resolução de problemas surgidos nos usos da linguagem e das línguas, o que não significa que não haja investigação teórica em LA.

Além de se enquadrar na perspectiva da LA, esta pesquisa caracterizou-se, ainda, como qualitativo-interpretativista. Nesse tipo de pesquisa, a realidade não pode ser considerada independente do indivíduo pelo fato de ser construída por esse indivíduo. Assim, o pesquisador não tem como se tornar neutro, uma vez que os fatos a serem pesquisados são indissociáveis da sua figura (MOITA LOPES, 2005), sendo ele parte integrante do processo de construção do conhecimento, interpretando os fenômenos e atribuindo-lhes um significado. Este estudo foi feito, assim, sob a ótica da pesquisa interpretativista por estar concentrado numa análise de traços e não numa mera descrição estatística de informações.

Outro viés metodológico sobre o qual o estudo se fundamenta é o da análise de conteúdo. Para Bardin (2006), a análise de conteúdo consiste num conjunto de técnicas de análise das comunicações. Para isso, faz uso de procedimentos sistemáticos e objetivos de descrição do conteúdo das mensagens. A análise de conteúdo tem sido muito usada em pesquisas que se debruçam sobre materiais escritos, como é o caso desta pesquisa que ora apresentamos.

Para apresentar os resultados obtidos pelo estudo realizado, este artigo, após esta breve apresentação, traz uma rápida discussão teórica a respeito da produção de textos escritos e sua relevância na escola. Na sequência, apresentamos os corpora que foram analisados e a partir dos quais elaboramos os objetivos. Na parte de análise, apresentamos dados quantitativos e qualitativos acerca dos corpora em observação, momento em que mostramos de que forma o MD aborda as competências do ENEM, bem como apresentamos os gêneros do discurso privilegiados nas propostas de produção de texto escrito e dizemos se as condições de produção do texto são consideradas. Nas considerações finais, esclarecemos se as perguntas de pesquisa foram respondidas e se os objetivos foram ou não alcançados. $\mathrm{O}$ 
Volume, 14, número 1, ano 2018.

artigo termina com as referências bibliográficas, que mostram os autores que usamos ao longo deste texto.

\section{POR UMA TEORIA QUE ABRANJA O OBJETO CENTRAL: A PRODUÇÃO DE TEXTOS ESCRITOS}

Um estudo sobre a produção de textos escritos é relevante por considerarmos que a produção escrita exerce um papel determinante sobre certos acessos ao mundo tecnologizado no qual vivemos, além de ser um dos conteúdos mais relevantes de que se ocupa a escola. Seu domínio permite que o sujeito tenha acesso a um vasto conjunto de conhecimentos e capacidades, as quais lhe garantirão participação plena no mundo social, além do exercício de sua cidadania de forma consciente e ativa. Mais que isso, segundo Bakhtin (1979), a língua escrita se constitui num sistema extremamente complexo, usada para concretizar parte dos gêneros do discurso secundários. Por conta dessa complexidade, à escola, a mais importante agência de letramento (KLEIMAN, 2007), cabe o papel fundamental de dotar o aluno de estratégias que o tornarão capaz de ler e produzir esses gêneros complexos.

Na escola, a produção de textos escritos coloca o aluno não apenas como mero espectador, ou consumidor passivo de um produto elaborado por outra pessoa. A atividade de produzir um texto pode fazer do aluno o sujeito-autor de um artefato (o texto) por meio do qual se trabalha a língua, dando-lhe a oportunidade de reflexão e diálogo com outros textos. Além disso, a produção de texto é um dos geradores de interação entre o aluno e seus professores, dando a ele o direito de confronto e a possibilidade de experimentar diversas nuances.

Na aula de Língua Portuguesa, o texto escrito produzido pelo aluno é uma unidade de sentido o qual, para sua elaboração, mobiliza um conjunto de saberes lexicais, gramaticais e textuais/discursivos utilizados nas ações sobre a linguagem na relação com o outro, o seu interlocutor. Os PCN de Língua Portuguesa (BRASIL, 1998) valorizam a produção do texto pelo aluno quando afirmam que as ações pedagógicas começam e terminam pelo trabalho com o texto de sua autoria. Geraldi (2013) diz que a produção de textos é o ponto de partida e 
Volume, 14, número 1, ano 2018.

o de chegada de todo o processo de ensino e aprendizagem de língua, uma vez que a totalidade da língua só é revelada no texto, onde o sujeito projeta sua visão de mundo.

A importância da produção de texto escrito na escola tem sido demonstrada através de algumas propostas de ensino que a colocam em destaque. Porém, essa importância foi realmente evidenciada a partir da publicação dos PCN de Língua Portuguesa (BRASIL, 1997 e 1998). Em vários momentos, o referencial enfatiza a importância de desenvolver a produção de textos como aspecto essencial para a garantia do domínio no uso da língua.

Uma pesquisa acerca da produção de textos escritos é relevante considerando algumas das modificações notadas na maneira de propor e encaminhar o ensino de produção textual; modificações estas surgidas a partir da divulgação dos trabalhos de Vygotsky ([1934]2003) sobre a teoria da aprendizagem numa perspectiva sócio histórica; do Círculo de Bakhtin/Volochínov $(1981,1935,1979)$ com a teoria dos gêneros do discurso e da interação verbal; de Schneuwly, Dolz e colaboradores, com sua proposta didática para o ensino de francês/língua materna, adaptada à realidade de ensino do Brasil.

\section{APRESENTAÇÃO DOS CORPORA}

Como dito antes, um dos motivos pela escolha do material didático apostilado analisado aqui se deu pelo fato de ele ser usado por um grande número de alunos em nível nacional, incluindo a cidade de Jataí (GO). A Rede Pitágoras de Ensino tem um grande alcance no segmento privado de Educação Básica no país, com abrangência nacional e internacional, como também já foi dito.

O apostilado destinado ao Ensino Médio é composto por três volumes, sendo um por ano em cada uma das três séries. Segundo o manual do professor (MP - p. 07), cada volume é dividido nas seções 'Para compartilhar'; 'Para explorar'; 'Para produzir textos'; 'Síntese: para resumir'; 'Para conectar'. O interesse central, naturalmente, será pela seção em que o aluno será encaminhado para a produção de textos escritos: 'Para produzir textos'.

Ainda segundo o MP (p. 07), na seção de produção de texto são apresentadas propostas de produção do gênero estudado no capítulo, bem como são apresentadas propostas de escrita de concursos vestibulares e do próprio ENEM. 
Volume, 14, número 1, ano 2018.

A organização estrutural do material se dá com a apresentação de quatro unidades em cada série. Cada unidade é composta por dois capítulos, totalizando oito no final da série. O livro do professor apresenta, para cada capítulo, habilidades específicas que se espera serem alcançadas pelo aluno, bem como o número de semanas que o professor deve usar para cada capítulo e ainda as estratégias de ensino que devem ser adotadas para o desenvolvimento dos conteúdos. Também é oferecido ao professor comentários de questões e textos complementares. No final do livro aparecem referências citadas e orientações de leitura teórica para o professor.

Segundo informações obtidas no site da Rede Pitágoras, o material didático do Ensino Médio, além de contemplar todos os conteúdos previstos nos programas de vestibulares e do ENEM, apresenta consistência teórica, abordagem diversificada, contextualização e problematização dos temas tratados, evidenciando o trabalho do professor como mediador e do aluno como agente de sua aprendizagem ${ }^{9}$.

\section{UM OLHAR DE ANALISTA SOBRE OS DADOS}

Usamos como fonte para a geração e análise dos dados a matriz de referência para Redação do exame do ENEM. Essa matriz, elaborada pelo INEP com a colaboração de especialistas, foi criada com o intuito de operacionalizar o exame. Foram referências essenciais para a estruturação do ENEM os Parâmetros Curriculares Nacionais do Ensino Médio (BRASIL, 2000) e as Orientações Curriculares para o Ensino Médio (BRASIL, 2006).

A matriz de referência traz cinco competências, apresentadas na sequência. Para cada competência expressa na Matriz existem níveis de conhecimento associados a essas competências, indo de 1 a 5.

Figura 1: Competências da prova de Redação ENEM

\begin{tabular}{|l|}
\hline \multicolumn{1}{c|}{ Competências } \\
\hline I - Demonstrar domínio da norma padrão da língua escrita \\
\hline $\begin{array}{l}\text { II - Compreender a proposta de redação e aplicar conceitos das várias } \\
\text { áreas de conhecimento para desenvolver o tema, dentro dos limites } \\
\text { estruturais do texto dissertativo-argumentativo }\end{array}$ \\
\hline III - Selecionar, relacionar, organizar e interpretar informações, fatos, \\
\hline
\end{tabular}

\footnotetext{
${ }^{9}$ http://www.redepitagoras.com.br/ensino-medio. Acesso em 21 de junho de 2017.
} 
Volume, 14, número 1, ano 2018.

\begin{tabular}{|l|}
\hline opiniões e argumentos em defesa de um ponto de vista \\
\hline IV - Demonstrar conhecimento dos mecanismos linguísticos \\
necessários para a construção da argumentação \\
\hline V - Elaborar proposta de solução para o problema abordado, \\
respeitando os valores humanos e considerando a diversidade \\
sociocultural
\end{tabular}

\section{Fonte: Guia do Participante do ENEM. Elaboração própria}

Acabamos de dizer que as competências da prova de Redação serviram como categorias para a geração e análise quantitativa e qualitativa dos dados. Do ponto de vista quantitativo, procedemos a uma apresentação de dados percentuais, intencionando mostrar o montante de propostas de produção escrita do apostilado, em relação a um valor total, que se encaixam em cada uma das competências. Em se tratando da análise qualitativa, apresentamos um (01) exemplo de proposta de produção escrita que aparece no MD, indicando que competência foi trabalhada, apontando, com base nos teóricos da área, as contribuições que atividades daquele tipo podem trazer para o aluno.

Também serviram como categorias para a geração e análise quantitativa e qualitativa dos dados os integrantes das condições de produção, os quais devem estar presentes numa proposição de escrita de textos: finalidade para a qual determinado texto será produzido, a especificidade do gênero, os locais de circulação daquele gênero, o interlocutor para o qual o gênero se destina e os temas propostos para discussão e depois produção. Dados quantitativos foram apresentados sob forma de um gráfico, apontando as ocorrências das condições de produção nas atividades propostas pelo MD. Houve, também, apresentação de um (01) exemplo ilustrativo com abordagens analíticas a respeito de como essas condições foram trabalhadas.

Uma das tarefas integrantes desta pesquisa consistiu num levantamento dos gêneros que são apresentados ao aluno para a produção escrita, observando se existia diversidade deles. Isso porque é de conhecimento que o trabalho com a diversidade de gêneros traz inúmeros benefícios ao aluno num programa de ensino de Língua.

Na sequência, apresentamos os gêneros propostos ao aluno para produção escrita ao longo dos volumes. Por questão de espaço, desconsideramos as repetições de um mesmo gênero proposto para produção mais de uma vez num mesmo volume. 
Volume, 14, número 1, ano 2018.

\begin{tabular}{|c|c|c|}
\hline Volume 1 & Volume 2 & Volume 3 \\
\hline \multirow[t]{2}{*}{ Conto } & Parágrafo-padrão & \multirow[t]{2}{*}{ Parágrafo-argumentativo } \\
\hline & Dissertativo & \\
\hline Texto narrativo & \multirow{2}{*}{$\begin{array}{l}\text { Parágrafo dissertativo } \\
\text { argumentativo }\end{array}$} & Artigo de opinião \\
\hline Notícia & & Dissertação-argumentativa \\
\hline \multirow[t]{2}{*}{ Crônica } & Parágrafo-padrão & \multirow[t]{2}{*}{ Campanha comunitária } \\
\hline & Relato & \\
\hline Comentário & Reportagem & \multirow[t]{2}{*}{ Carta Aberta } \\
\hline Relato & \multirow{2}{*}{$\begin{array}{l}\text { Texto dissertativo- } \\
\text { argumentativo }\end{array}$} & \\
\hline Texto opinativo & & \multirow[t]{2}{*}{ Editorial } \\
\hline Parágrafo & \multirow[t]{2}{*}{ Texto expositivo } & \\
\hline Texto descritivo & & \multirow[t]{2}{*}{ Carta ao leitor } \\
\hline \multirow[t]{2}{*}{ Parágrafo padrão } & $\begin{array}{l}\text { Texto expositivo- } \\
\text { argumentativo }\end{array}$ & \\
\hline & Discurso expositivo & \multirow[t]{3}{*}{ Texto dissertativo } \\
\hline \multirow[t]{2}{*}{ Infográfico } & Parágrafo argumentativo & \\
\hline & Artigo de opinião & \\
\hline Total 11 & Total 12 & Total 08 \\
\hline
\end{tabular}

Fonte: Apostilado da Rede Pitágoras. Elaboração própria

Não consideramos que tenha havido variação de gêneros apresentados para produção ao longo das três séries, especialmente no Volume 3, em que só ocorreram 08 (oito) gêneros diferentes propostos para escrita. Nesse sentido, consideramos que houve menos contribuição com o aluno no sentido de que um maior número de gêneros favoreceria a apropriação de uma variedade maior de letramentos, considerando que quanto maior a variedade de gêneros produzidos, maiores as chances de o aluno ter domínio sobre um número maior de letramentos.

Em relação a observar como as condições de produção do texto escrito foram consideradas pelas/nas propostas de produção apresentadas pelo material em análise, os dados quantitativos mostram o seguinte.

\section{Gráfico 1: Condições de produção do texto escrito}


Volume, 14, número 1, ano 2018.

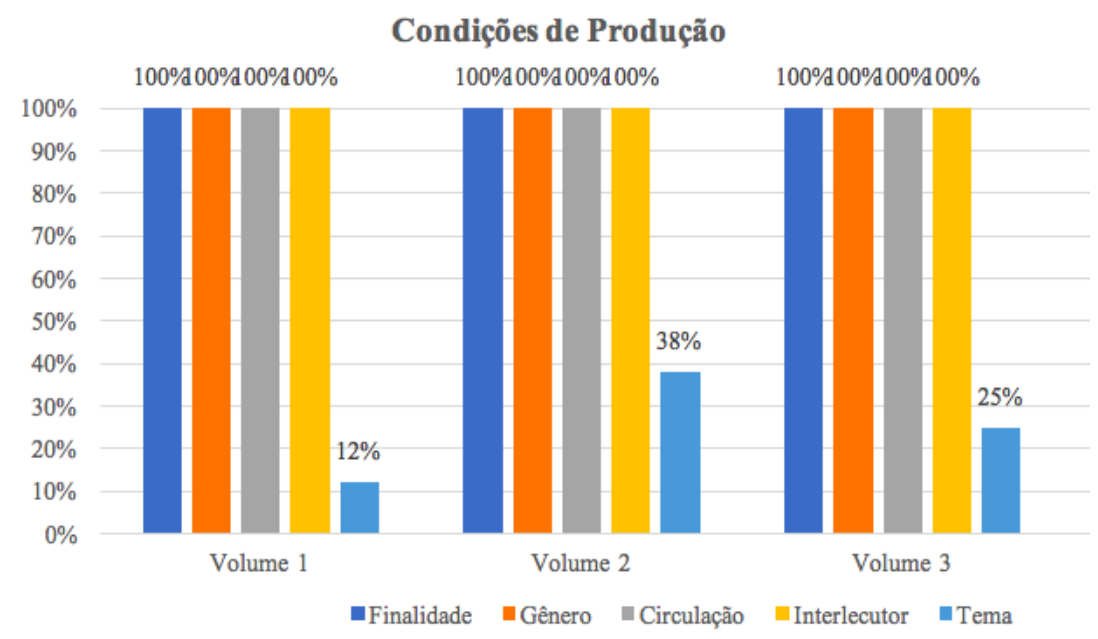

Fonte: Apostilado da Rede Pitágoras. Elaboração própria

Ressaltamos que os dados percentuais apresentados foram alcançados levando-se em conta o montante de atividades de produção de texto escrito apresentadas para os alunos. No Vol. 1, foram apresentadas um total de 25 (vinte e cinco) propostas de produção de texto escrito; no Vol. 2, 29 (vinte e nove) propostas; no Vol. 3, 24 (vinte e quatro) propostas. Os 3 (três) volumes totalizam 78 (setenta e oito) propostas de produção de texto escrito.

Os dados quantitativos há pouco mostrados indicam uma excelente abordagem do contexto de produção nos elementos finalidade, gênero, circulação e interlocutor. $O$ trabalho de produção textual considerando o contexto de produção é imprescindível, já que o contexto de produção é um dos fatores que faz com que o texto possa ser de fato considerado um texto, e não um amontoado de frases sem conexão textual e discursiva. Nesse sentido, Bronckart (2006, p. 93) diz que "o contexto de produção pode ser definido como o conjunto dos parâmetros que podem exercer uma influência sobre a forma como um texto é organizado". $\mathrm{Na}$ fala do autor, nota-se que a definição do contexto de produção é fator determinante para a forma como será feito um texto.

Assim, consideramos que as contribuições com o aluno são memoráveis quando a proposta de produção de texto apresenta ao aluno qual a finalidade daquele gênero que está sendo proposto para escrita. Como no dizer de Bakhtin (1979) cada esfera de atividade humana elabora seus tipos relativamente estáveis de enunciado, em cada uma dessas esferas um gênero apresentará uma finalidade. Assim, se o aluno for formando consciência a esse 
Volume, 14, número 1, ano 2018.

respeito, poderá ter mais êxito ao elaborar um texto, considerando a finalidade a qual tal gênero apresenta nesta ou naquela esfera.

Com relação ao elemento do contexto de produção 'gênero', percebemos que apresentar ao aluno o gênero que será abordado e depois produzido ampliará seu repertório a respeito dos gêneros que circulam socialmente e que aparecem na escola. Todas as propostas de produção do material didático não só anunciam o nome do gênero a ser trabalhado naquele momento, como também anunciam um breve conceito a seu respeito.

Sobre o contexto de circulação, um gênero deve ser elaborado considerando, dentre outros fatores, o local, ou locais, onde circulará. Isso fica muito claro quando vemos as palavras de Bakhtin (1979, p. 261) quem diz que "o enunciado reflete as condições específicas e as finalidades de cada uma das esferas, não só por seu conteúdo (temático) e por seu estilo verbal [...] mas também, e sobretudo, por sua construção composicional” (ênfase adicionada). Assim, pelas palavras do filósofo da linguagem fica fácil perceber o quanto a esfera de circulação do gênero é relevante nas escolhas temáticas, estilísticas e composicionais que o locutor fará para a produção de seu enunciado. Nesse sentido, consideramos que o material em análise prestou um importante papel ao considerar o contexto de circulação em todas as propostas de produção de texto escrito.

Ainda em relação às contribuições do material para a apropriação das condições de produção do texto pelo aluno, notamos, nos dados quantitativos apresentados há pouco, que a indicação de quem é o interlocutor para quem os textos produzidos se dirigem ocorreu em todos os casos. Sabemos que a escrita produzida na escola muitas vezes não passa de um simulacro da realidade, já que, em grande parte, o único leitor e o interlocutor real a quem o texto produzido pelo aluno se dirige é o professor, caracterizando este texto, no entendimento de Marcuschi e Cavalcanti (2005), como texto endógeno, pelo fato de que se origina e se esgota nele mesmo. Por mais que saibamos que esta é a realidade vigente, consideramos que a indicação do interlocutor que não seja o professor é um elemento relevante, por fazer com que o aluno reflita a respeito da pessoa para quem seu texto ficticiamente se dirige. Voltando mais uma vez aos elementos que constituem o gênero, na perspectiva de Bakhtin (1979, p. 266), vemos que ele diz que o interlocutor deve ser considerado no momento de aplicar àquilo que está sendo produzido um estilo, levando em conta, dentre outros fatores, "o tipo de relação 
Volume, 14, número 1, ano 2018.

entre o locutor e os outros parceiros da comunicação verbal (relação com o ouvinte, ou com o leitor, com o interlocutor, com o discurso do outro, etc) $[\ldots]$ ".

Apesar de considerarmos relevante a forma como o material em análise abordou a maioria dos elementos que constituem as condições de produção do texto, os dados quantitativos mostram que o tema é pouco considerado no apostilado, com (12\%), (38\%) e (25\%) de abordagem em cada um dos três volumes, respectivamente. Ao observarmos o tratamento dado ao tema pelo $\mathrm{MD}$, notamos que, muitas vezes, dizia respeito ao assunto ou à presença de alguns textos problematizadores, apresentados apenas em formas de links que o aluno pode consultar caso ache necessário.

Ao longo dos volumes, a dicotomia tema/assunto é frequentemente utilizada de forma equivocada pelos organizadores do apostilado, o que pode ocasionar dubiedade também para os estudantes. Enquanto o assunto se reduz àquilo sobre o que se fala, recorrendo unicamente ao sistema linguístico, o tema se constitui em situações reais de uso, nas quais se tem a presença de interlocutores interagindo socialmente. Segundo Bakhtin/Volochínov (2010, p.129), "o tema é um sistema de signos dinâmico e complexo, que procura adaptar-se adequadamente às condições de um dado momento da evolução. O tema é uma reação da consciência em devir ao ser em devir". Portanto, o tema sempre possui um valor social, sendo sempre resultado de uma ou várias interações.

Dentro da produção de textos, a dicotomia tema/assunto é muito marcante. O assunto se refere a algo mais genérico (Cidadania, Ecologia, Terrorismo, por exemplo), que pode ser desdobrado em temas, recortes desse assunto, algo ideológico que dá margem a uma discussão. Suponhamos que na proposta de escrita de um texto dissertativo-argumentativo haja uma abordagem sobre ecologia, a qual, no final, culmina no tema solicitado: desenvolvimento e preservação ambiental - como conciliar os interesses em conflito $^{10}$. Percebemos que não será todo ponto de partida dentro do amplo assunto Ecologia que será válido, já que o tema foi delimitado para "desenvolvimento e preservação ambiental" e deve ser seguido para que não ocorra fuga do tema.

${ }^{10}$ Retirado http://educacao.globo.com/portugues/assunto/redacao/enem-2001-tema-da-redacao.html. Acesso em 03 de abril de 2017. 
Volume, 14, número 1, ano 2018.

É pelo de fato de esse material ser o último contato do aluno com a produção de textos antes do ENEM que o esclarecimento a respeito da diferença entre tema e assunto se faz necessário. A prova exige boa capacidade de leitura e interpretação do enunciado da redação, além de deixar claro que o aluno deve discorrer sobre o tema proposto. Caso isso não ocorra, ele pode falhar em uma das exigências do exame e cair na "fuga" do tema, o que zera a sua nota. Diante disso, a parca abordagem temática dentro do apostilado, além de não oferecer subsídios para reflexão do aluno acerca daquilo que deverá ser escrito, ainda poderá causar imprecisão sobre o significado da dicotomia tema/assunto. Seria necessário deixar claro para o aluno essa diferença, além de sempre oferecer textos problematizadores, apresentando vários pontos de vista a respeito de algo, assim como é feito na proposta de produção de texto do ENEM.

Apesar de os dados quantitativos indicarem que houve pouca abordagem temática ao longo dos volumes, apresentamos um exemplo ilustrativo em que essa questão foi considerada de forma produtiva. Optamos por apresentar exemplo ilustrativo apenas referente ao tema pelo fato de que, dada a importância de se ter conhecimento a respeito do que é o tema e de sua relevância para a produção de texto, se houvesse muitos casos de abordagem como a do exemplo que apresentamos, o qual consideramos como produtivo, as contribuições para o aluno seriam grandiosas.

O referido exemplo foi retirado do Volume 2 (dois), Unidade 2 (dois), Capítulo 3 (três). A unidade em destaque, que visa trabalhar com o aspecto tipológico 'Exposição', traça, primeiramente, uma breve introdução sobre o que seria e como seria o ato de expor e informar. Propõe, ainda, ao longo do capítulo, mostrar as diferentes formas de organização do discurso expositivo, além de explorar sua estrutura e seus efeitos discursivos dentro do texto.

Em seguida, apresenta o gênero que será trabalhado dentro do capítulo: Reportagem. Para isso, expõe a imagem de uma folha de jornal com a seguinte manchete: “Aventura da adoção traduzida em amor" (p. 34). A referida reportagem fala de um casal paraibano que viaja à China para garantir células-tronco para o filho adotado. A partir disso, introduz o gênero com um parágrafo informativo sobre o que é uma reportagem, como estruturá-la, quais são os meios de veiculação, o público, o título, dentre outros aspectos referentes ao contexto de produção do texto, para, em seguida, dar início às atividades que auxiliarão na construção desse conceito. Ao todo são dezoito (18) atividades que trabalharão 
Volume, 14, número 1, ano 2018.

esse gênero, distribuídas entre abordagens a respeito da decodificação, compreensão, interpretação e produção textual.

A proposta de produção escrita escolhida para representar um trabalho ilustrativo sobre a abordagem temática apresenta três textos problematizadores (p. 45), sendo uma notícia e um artigo, que trabalham o lado mais informativo do tema, acrescentando pontos de vista, possivelmente, não levantados pelo próprio aluno, e uma charge reflexiva e crítica sobre o tema. Em seguida, é indicado que sejam seguidas algumas instruções para a construção do texto.

Nossa apreciação valorativa positiva em relação a esse exemplo ilustrativo está na apresentação dos três textos problematizadores. Ao apresentar textos que falam sobre o tema em diferentes vieses, o material didático avança além do que, na maioria das vezes, ele mesmo fez, que foi abordar tão somente o assunto, deixando de oferecer ao aluno diferentes posições a respeito daquilo sobre o que se escreveria depois. Ao apresentar textos problematizadores, que podem constituir a coletânea que poderá ser usada pelo aluno em seu próprio texto, o material didático não só favorece a construção dos argumentos como também tende a familiarizar o aluno com a estrutura composicional da prova do ENEM, a qual traz uma coletânea de textos problematizadores que colaborarão com a construção dos argumentos do aluno.

Na sequência, apresentamos a proposta apresentada pelo material ao aluno.

\section{Quadro 1. Atividade ilustrativa - Abordagem Temática}

\section{Volume 2 - Unidade 2 - Capítulo 3 - p. 45}

18- Com base na leitura dos textos motivadores e nos conhecimentos construídos ao longo de sua formação, redija um texto dissertativo-argumentativo, em norma padrão da Língua-Portuguesa, sobre o tema "Os desafios dos brasileiros em conciliar a produção e a gestão de lixo", apresentando proposta de ação social que respeite os direitos humanos. Selecione, organize, e relacione, de forma coerente e coesa, argumentos e fatos para defender seu ponto de vista.

\section{Fonte: Apostilado da Rede Pitágoras. Elaboração própria}

A respeito da relevância do tema, Bakhtin/Volochínov (2010, p. 128) tece algumas considerações sobre tema e significação da língua, comparando os dois conceitos e lançando definições. Para ele, o tema "é um sistema de signos dinâmico e complexo, que 
Volume, 14, número 1, ano 2018.

procura adaptar-se adequadamente às condições de um dado momento da evolução. [...] A significação é um aparato técnico para a realização do tema". Sendo assim, faz-se impossível traçar uma fronteira entre a significação e o tema, já que não há tema sem significação, e viceversa. Além disso, segundo o mesmo autor (p. 129), "é impossível designar a significação de uma palavra isolada, sem fazer dela o elemento de um tema, isto é, sem construir uma enunciação, um “exemplo"”. Percebe-se, portanto, que uma boa abordagem temática, antes de realizar uma produção textual, oferece ao aluno uma significação para seu trabalho, para que esse não fique ausente de sentido.

Notamos, assim, que uma boa abordagem temática se faz na presença de bons textos problematizadores - de preferência de gêneros e opiniões distintas - como foi feito pela proposta apresentada há pouco. Essa abordagem é necessária para que haja conflito de opiniões, permitindo ao aluno uma reflexão sobre os diversos pontos de vista que podem abarcar o tema, o que, consequentemente, poderá auxiliá-lo na construção de um texto mais crítico e elaborado, assim como pede a proposta de produção textual do ENEM. De acordo com o Guia do Participante (BRASIL, 2016, p. 17), o tema constitui "o núcleo das ideias sobre as quais a tese se organiza". Em um âmbito mais abrangente, o assunto recebe uma delimitação por meio do tema, ou seja, um assunto pode ser abordado por diferentes temas.

Em se tratando de levantamento quantitativo a respeito das competências ao longo das propostas de produção de texto, apresentamos o gráfico na sequência que mostra como se deu essa presença em números percentuais

\section{Gráfico 2: Competências trabalhadas}

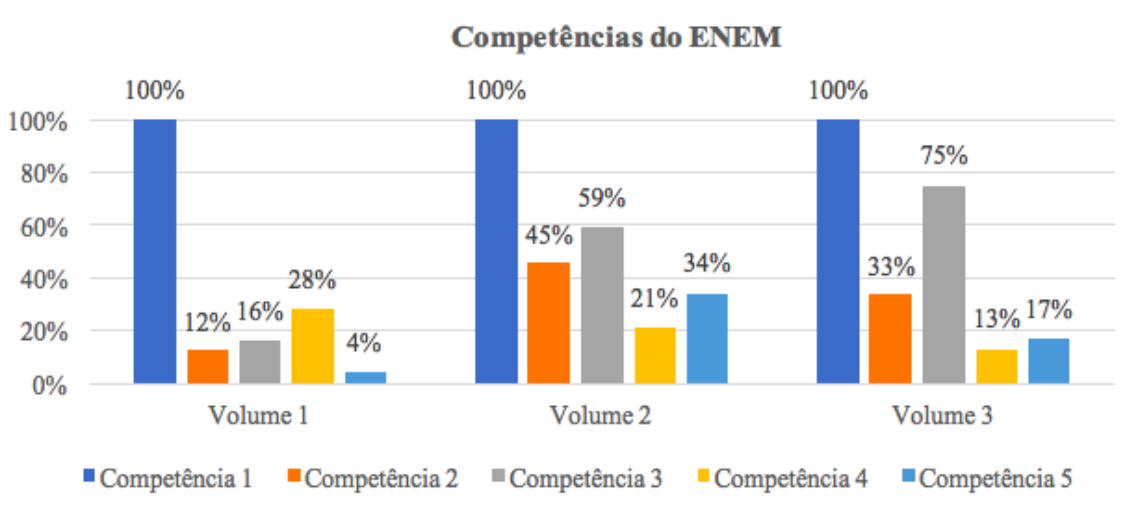

Fonte: Apostilado da Rede Pitágoras. Elaboração própria 
Volume, 14, número 1, ano 2018.

Voltando à proposta de produção de texto apresentada há pouco, nota-se que ela aborda a competência 3 (três) - selecionar, relacionar, organizar e interpretar informações, fatos, opiniões e argumentos em defesa de um ponto de vista (tarefa solicitada no final da proposta apresentada). Houve (59\%) de ocorrências no volume 2, de onde a proposta foi extraída. Essa competência requer do aluno muita leitura de mundo e atualidades, já que tudo que deverá ser escrito na redação precisa estar fundamentado. Para isso, ele pode se embasar, por exemplo, em dados estatísticos, analogias, metáforas e/ou comparações, fatores com causa e consequência, enumerações e citações.

Tendo em vista o caráter argumentativo do texto, podemos considerar que a persuasão é um recurso importante para a objetivação do ponto de vista também solicitado pela proposta em análise. Para Citelli (2003), são a partir das experiências acumuladas, leituras realizadas, informações obtidas, do desenvolvimento da capacidade de compreender e, acima de tudo, de deixar claro para o outro aquilo que se deseja dizer, que o aluno começa a compreender os objetivos de convencimento e/ou persuasão.

Assim sendo, antes que o aluno alcance tal nível persuasivo para defender seu ponto de vista a respeito de algum tema, ele precisa passar por uma série de pré-requisitos que podem contribuir para sua formação como leitor, escritor, aluno e cidadão, já que, segundo o autor há pouco citado, (p. 19) "a visão que temos das coisas, dos homens, do mundo é também constituída pelo que se chama de formação discursiva". Ao defender o seu ponto de vista, o aluno poderá, portanto, pensar, expor e opinar sobre determinado tema por meio de uma argumentação lógica, coerente e coesa, trabalhando sua habilidade argumentativa e refletindo sobre questões sociais.

Outra competência que o exemplo em observação contempla é a de número 5 (cinco), a qual solicita que o aluno elabore uma proposta de ação social que respeite os direitos humanos. Os dados quantitativos nos mostram o total de (34\%) de ocorrência desta competência no volume de onde o exemplo foi retirado.

Essa competência é o último - não menos importante - critério a ser avaliado na redação do ENEM. Esse ponto é obrigatório na prova, uma vez que a proposta da redação do ENEM procura fazer com que a pessoa reflita sobre a sociedade. Para muitos candidatos, a proposta de intervenção, apesar de importante, é um pouco nebulosa. 


\section{HIVERARIUS REVISTAELETRONICA

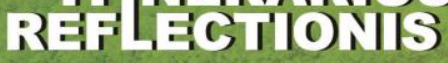

Volume, 14, número 1, ano 2018. 
Volume, 14, número 1, ano 2018.

\section{CONSIDERAÇÕES FINAIS}

Ao finalizarmos este estudo, retomando a primeira pergunta de pesquisa e o primeiro objetivo específico (o baixo desempenho dos alunos da unidade escolar usuária do sistema de apostilado da Rede Pitágoras de Ensino em 2014, em Jataí (GO), na prova de Redação do Exame Nacional do Ensino Médio (ENEM), está associado à concepção de produção escrita adotada pelo material didático (MD), que desconsidera as competências expressas na matriz de referência para Redação?/analisar se os saberes (capacidades discursivas - SCHNEUWLY \& DOLZ, 2010) mobilizados pelas propostas de produção escrita do apostilado da Rede Pitágoras (Ensino Médio) vão ao encontro das competências da Matriz de Referência para Redação do ENEM, considerando a prioridade que têm para a produção de um texto escrito de qualidade), notamos que existe oscilação em relação à mobilização do apostilado da Rede Pitágoras de Ensino no que diz respeito às competências da prova de Redação do ENEM, exceto em relação à competência 1 (Demonstrar domínio da norma padrão da língua escrita), presente em todas as setenta e oito (78) propostas de produção de texto escrito apresentadas ao aluno.

A oscilação em relação à abordagem feita acerca das competências no ENEM parece nos mostrar que é provável que haja contribuições no que se refere a se apropriar bem das competências a ponto de usá-las bem na redação do ENEM. A exceção a isso que acabamos de pontuar estaria no Vol. 1, que foi o que menos mobilizou as competências 2 (dois) a 5 (cinco).

Sobre as outras perguntas da pesquisa (o baixo desempenho dos alunos se deve a uma metodologia adotada pelo MD a qual privilegia um ensino mais normativo, baseado em atividades de codificação, decodificação?/ a concepção de linguagem e de texto escrito que se sobressai nas atividades de produção de texto do MD é aquela que favorece os sentidos presentes na linguagem em uso?), julgamos que a resposta à primeira é negativa. A análise qualitativa nos mostrou que a metodologia adotada pelo MD para a produção de texto privilegia um ensino menos normativo e muito mais baseado na compreensão ativa (BAKHTIN/VOLOCHÍNOV, 1981). Os dados quantitativos e a atividade ilustrativa apresentada para a análise qualitativa nos mostra que o material considera os elementos inerentes ao contexto de produção, já que, dentre outras ações, chama a atenção do aluno para 
Volume, 14, número 1, ano 2018.

o interlocutor a quem o texto se destina, o contexto de circulação do texto, o interlocutor, além de favorecer o debate dos alunos entre si e a pesquisa, não só no material didático. $\mathrm{O}$ problema, como visto nas análises quantitativa e qualitativa, está associado à abordagem sobre o tema, tão pouco considerado em relação aos demais elementos das condições de produção em todo o MD.

Sobre a segunda pergunta há pouco apresentada, na análise qualitativa foi perceptível que a concepção de linguagem e de texto escrito que se sobressai nas atividades de produção de texto do apostilado é aquela que dá relevância à escrita de um texto em que o contexto de produção se faz presente, por mais que a abordagem temática tenha sido menor do que poderia, como já mencionado.

Sabemos que não podemos perder de vista que, como já dissemos em Silva e Carvalho (2017), o material didático participa da responsabilidade sobre o sucesso ou não do aluno, mas constitui apenas uma parte do processo, sendo o professor a outra parte. A mediação do professor no processo de ensino e aprendizagem de escrita é imprescindível, não só por ser ele a parte mais experiente da relação professor/aluno, mas porque "a mediação oportuna e construtiva do professor pode representar uma estratégia pedagógica muito eficiente" (BORTONI-RICARDO e SILVA, 2015, p. 110).

Ao finalizarmos o estudo, hipotetizamos que os alunos da escola usuária do MD que analisamos devem ter tido menor desempenho que os alunos das demais unidades da rede privada da cidade não em decorrência da metodologia de ensino de língua apresentada pelo material. Não temos condições de levantar hipóteses acerca do que pode ter motivado esse desempenho menor porque não observamos como o professor de produção de texto escrito desenvolvia a aula usando o MD como apoio. Como dissemos há pouco, o professor tem um importante papel da didatização dos saberes para que sejam melhor apreendidos pelos alunos.

Num estudo futuro, podíamos participar das aulas, vendo como o professor direciona as atividades e com que outros materiais trabalha, visando a um maior aproveitamento por parte dos alunos do que o MD traz.

\section{REFERÊNCIAS}

ARRUDA, E. E. de, KINJO, C. N. \& BARBOZA, M. M. O processo de mercantilização do ensino no nível fundamental e médio em uma capital brasileira de porte médio. Mimeo, s/d. 
Volume, 14, número 1, ano 2018.

BAKHTIN, M. Questões de literatura e estética. São Paulo: UNESP/HUCITEC, 1975.

BAKHTIN, M. Os gêneros do discurso. In . Estética da criação verbal. São Paulo: Martins Fontes, 1979. p. 277-326.

BAKHTIN, M./VOLOCHINOV, V. N. Marxismo e filosofia da linguagem. São Paulo: Hucitec, 1981.

BARDIN, L. Análise de conteúdo. Lisboa: Edições 70, 2006.

BORTONI-RICARDO, S. M e SILVA, M. da G. Mediação em sala de aula. In: FERNANDES, E. M. da F. e SOUSA FILHO, S. M. de. Leitura: ações de mediação pedagógica. Campinas/SP: Pontes Editores, 2015. pp.109-115.

BRASIL (SEF/MEC). Parâmetros Curriculares Nacionais $-1^{\circ}$ e $2^{\circ}$ Ciclos do Ensino Fundamental. Língua Portuguesa. Brasília, DF: SEF/MEC, 1997. 92 p.

BRASIL. Parâmetros Curriculares Nacionais - 3o e 4o Ciclos do Ensino Fundamental. Língua Portuguesa. Brasília, DF: SEF/MEC, 1998. 107 p.

BRASIL. Ministério da Educação. Secretaria de Educação Média e Tecnológica. Parâmetros curriculares nacionais: ensino médio. Brasília: MEC/SEMTEC, 2000.

BRASIL/MEC/SEB. Orientações curriculares para o ensino médio: Linguagens, códigos e suas tecnologias. Secretaria de Educação Básica. - Brasília: Ministério da Educação, Secretaria de Educação Básica, 2006. 239 p.

BRASIL. Guia do Participante: a redação do ENEM. 2016. Disponível em: < http://download.inep.gov.br/educacao_basica/enem/guia_participante/2016/manual_de_redac ao_do_enem_2016.pdf >. Acesso em 13 de junho 2017.

BRONCKART, J. P. Atividade de linguagem, discurso e desenvolvimento humano. Campinas: Mercado de Letras, 2006.

BUNZEN, C. O antigo e o novo testamento: livro didático e apostila escolar. Ao pé da letra, v. 3.1, p. 35-46, 2001. Disponível em: http://aopedaletra.net/. Acesso em 05 de março de 2016.

CITELLI, A. O texto argumentativo. São Paulo: Scipione, 2003.

CHOPPIN, A. Le manuel scolaire, une fausse évidence historique. Histoire de l'éducation, $\mathrm{n}^{\circ} 117$, janeiro-março, 2008, p. 7-56.

GERALDI, J. W. Portos de passagem. São Paulo: Martins Fontes, 2013. 
Volume, 14, número 1, ano 2018.

KLEIMAN, A. Letramento e suas implicações para o ensino de língua materna. Signo, v. 32 $n^{\circ} 53$, p. 1-25, dez, 2007.

MARCUSCHI, B. O que nos dizem o SAEB e o ENEM sobre o currículo de língua portuguesa para o ensino médio? In: BUNZEN, C.; MENDONÇA, M. (Org.). Português no ensino médio e formação do professor. São Paulo: Parábola, 2006. p.57-82.

MARCUSCHI, E. \& CAVALCANTE, M. Atividades de escrita em livros didáticos de língua portuguesa: perspectivas convergentes e divergentes. In: COSTA VAL, M. da G. \& MARCUSCHI, B. (Org.). O livro didático de língua portuguesa - letramento, inclusão e cidadania. Belo Horizonte: Autêntica, 2005. p. 237-260.

MOITA LOPES, L. P. da. Oficina de linguística aplicada. Campinas, Mercado de Letras, 2005.

MORIN, E. Educação e complexidade: os sete saberes e outros ensaios. São Paulo: Cortez, 2002.

PEDROSA, M. C. N. S. As atividades de produção textual escrita em livros didáticos de português: caminhos e descaminhos na formação de produtores de textos. 2006. $230 \mathrm{f}$. Dissertação (Mestre) - Programa de Estudos Pós-Graduados em Linguistica Aplicada e Estudos da Linguagem, Pontifícia Universidade Católica de São Paulo, São Paulo/SP, 2006.

ROJO, R. H. R. Fazer linguística aplicada em perspectiva sócio-histórica: privação sofrida e leveza do pensamento. In: MOITA LOPES, L. P. da (org.). Por uma linguística aplicada indisciplinar. Parábola Editorial: São Paulo, 2006. p. 253-276.

SALOMÃO, R. C. S. Apostilados, fascículos ou livros didáticos de Língua Portuguesa? - um breve panorama do Ensino Médio brasileiro. Língua, Literatura e Ensino, v. 2, maio 2007. Disponível em: http://www.iel.unicamp.br. Acesso em 05 de março de 2016.

SCHNEUWLY, B. Le langage écrit chez l'enfant - la production des textes informatifs et argumentatifs. Lausanne: Delachaux et Niestlé, 1988.

SCHNEUWLY, B. \& DOLZ, J. Os gêneros escolares - das práticas de linguagem aos objetos de ensino. In: SCHNEUWLY, B. \& DOLZ, J. et al. Gêneros orais e escritos na escola. Campinas: Mercado de Letras, 2010. p. 71-91.

SILVA, S. R. da e CARVAlHO, T. L. Produção de Texto Escrito no Ensino Médio: competências requeridas pela avaliação de redação do enem em (des)uso no livro didático de português. Caminhos em linguística aplicada, Volume 16, Número 1, $1^{\circ}$ sem 2017. p. 1-25.

VIGNOLI, A. P. F.; MARTINS, I. A. M. L.; BORGES, S. M. F. Produção de texto. Ensino Médio - 3 volumes. Belo Horizonte: Editora Educacional, 2015.

VYGOTSKY, L. S. (1934). Pensamento e linguagem. São Paulo: Martins Fontes, 2003. 